\title{
Fas regulates the apoptosis and migration of trophoblast cells by targeting NF- $\kappa B$
}

\author{
RUIHONG LAN* , YANG YANG ${ }^{*}$, JIE SONG, LING WANG and HUMIN GONG \\ Department of Obstetrics, Hainan General Hospital/Affiliated Hainan Hospital of \\ Hainan Medical College, Haikou, Hainan 570311, P.R. China
}

Received September 29, 2020; Accepted May 10, 2021

DOI: $10.3892 /$ etm.2021.10489

\begin{abstract}
Placental trophoblast apoptosis is a major pathological feature of preeclampsia. Fas has been reported to be highly expressed in the placentas of patients with preeclampsia. However, the role and underlying mechanisms of Fas in the pathogenesis of preeclampsia have not been elucidated. In the present study, the expression of Fas in JAR human choriocarcinoma cells was overexpressed and knocked down to determine the function and possible mechanism of Fas in trophoblast cells in the progression of preeclampsia. The results of flow cytometry, Cell Counting Kit- 8 and Transwell assays indicated that the overexpression of Fas promoted apoptosis, suppressed viability and impaired the migration of the human trophoblast cells. In addition, western blotting revealed that the overexpression of Fas increased the expression of nuclear factor $\mathrm{kB}(\mathrm{NF}-\mathrm{kB}), \mathrm{Bax}$, tumor necrosis factor $\alpha$ (TNF- $\alpha$ ) and interleukin-2 (IL-2), and decreased the expression of Bcl-2 at the protein level in trophoblast cells. By contrast, the knockdown of Fas decreased the apoptosis of trophoblast cells and increased their viability and migration. In addition, the knockdown of Fas suppressed the expression of $N F-\kappa B$, Bax, TNF- $\alpha$ and IL-2, and increased the expression of Bcl-2. Notably, the overexpression of NF- $\mathrm{B}$ p 65 attenuated the Fas knockdown-induced inhibition of apoptosis and acceleration of migration of the trophoblast cells. The overexpression of $\mathrm{NF}-\kappa \mathrm{B}$ in trophoblast cells also reversed the reduction in Bax expression and increase in $\mathrm{Bcl}-2$ expression induced by Fas knockdown in trophoblast cells. These results indicate that Fas regulates the apoptosis and migration of trophoblast cells by targeting $\mathrm{NF}-\kappa \mathrm{B}$, which suggests that the silencing of Fas is a promising therapeutic strategy for preeclampsia.
\end{abstract}

Correspondence to: Professor Humin Gong, Department of Obstetrics, Hainan General Hospital/Affiliated Hainan Hospital of Hainan Medical College, 19 Xiuhua Road, Haikou, Hainan 570311, P.R. China

E-mail: 15595895588@163.com

*Contributed equally

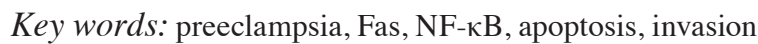

\section{Introduction}

Preeclampsia is a hypertensive disorder affecting 3-5\% of pregnant women and one of the three most frequent causes of maternal mortality (1) A total of $\sim 16 \%$ of maternal deaths can be attributed to hypertensive disorders (2). Immune disorders, shallow placental implantation, vascular endothelial damage, genetic factors and nutritional deficiencies have been considered as causative factors for preeclampsia (3). Several studies have shown that the reduced ability of trophoblasts to invade the spiral artery of the uterus decreases placental blood supply $(4,5)$ and increases the apoptosis of migratory trophoblasts in the placental tissue during the early stage of preeclampsia (6). At present, the pathogenesis of various preeclampsia phenotypes has not been fully elucidated. A deep understanding of trophoblast cell apoptosis and migration may reveal the pathogenesis of preeclampsia (7). Therefore, it is important to identify key regulatory molecules involved in the preeclampsia-associated apoptosis and migration of trophoblasts (8).

A number of molecules have been demonstrated to be associated with the apoptosis and migration of trophoblast cells in preeclampsia. For instance, let-7a has been reported to increase the apoptosis of trophoblast cells in preeclampsia by inhibiting the expression of Yes-associated protein 1 and Bcl-xl (9). In addition, exosome-secreted microRNA-133b has been demonstrated to suppress apoptosis and boost the proliferation and invasion of trophoblasts in preeclampsia by restricting the expression of serum/glucocorticoid regulated kinase 1 (10). Also, protein disulfide isomerase 3 has been shown to regulate trophoblast apoptosis and proliferation in preeclampsia via the E3 ubiquitin-protein ligase Mdm2/p53 pathway (11). The Fas/Fas ligand (FasL) system, which belongs to the tumor necrosis factor family of receptors and ligands, is one of the most common apoptotic pathways (12). Fas and FasL are widely distributed in various tissues where they regulate apoptosis in pregnancy during mammalian development (13). There is evidence to indicate that Fas and FasL genes contribute to the development of preeclampsia (14). Previous studies have shown that Fas is highly expressed in placental tissues during preeclampsia $(15,16)$. However, the specific role of Fas in preeclampsia is unclear.

Nuclear factor $\kappa \mathrm{B}(\mathrm{NF}-\kappa \mathrm{B})$ is a transcription factor that regulates the expression of various genes associated with tumorigenesis, apoptosis, inflammation and immune 
diseases (17). NF- $\mathrm{NB}$ can be activated through classical or alternative pathways (17). NF- $\mathrm{NB}$ in the placental tissue promotes the expression of cytokines, which induces immune and inflammatory reactions and placental cell damage, thereby accelerating the pathogenesis of preeclampsia $(18,19)$. The DNA-binding activity and nuclear localization of $\mathrm{p} 65$, a NF- $\kappa \mathrm{B}$ subunit, in the fetal membrane and myometrium influences the pathogenesis of preeclampsia (20). Therefore, the mechanism through which $\mathrm{NF}-\kappa \mathrm{B}$ regulates preeclampsia merits further exploration.

The present study aimed to investigate the underlying role of Fas and NF- $\mathrm{NB}$ in preeclampsia with the overarching goal of identifying suitable biomarkers for the screening and treatment of preeclampsia.

\section{Materials and methods}

JAR cell culture. JAR choriocarcinoma cells, a neoplastic trophoblast cell line, were obtained from the Cell Bank of the Chinese Academy of Sciences (Shanghai, China). The cells were cultured in DMEM (cat no. A4192101) supplemented with 10\% FBS (cat. no. 16140071) and 1\% penicillin/streptomycin (cat. no. 15140122; all Gibco; Thermo Fisher Scientific, Inc.) under a humidified environment with $5 \% \mathrm{CO}_{2}$ at $37^{\circ} \mathrm{C}$.

Vector construction and lentiviral infection. A lentiviral overexpression vector was designed and constructed based on the human full-length coding protein sequence of Fas (GenBank accession no.: NM_000043) by GeneChem, Inc. A knockdown lentiviral vector was constructed to express small interfering RNAs targeting the human Fas sequence, and a negative control (NC) lentivirus with a non-targeting sequence was also designed. The short hairpin RNA (shRNA) sequence used for the knockdown of Fas was 5'-GCGTATGACACATTG ATTAAA-3' and the non-targeting sequence was 5'-TTCTCC GAACGTGTCACGT-3'. The shRNA sequences were cloned into a GV248 vector (GeneChem, Inc.) to produce lentiviral vectors. All vectors carried green fluorescent protein. The vectors $(100 \mathrm{nM})$ and packaging plasmids $[\mathrm{psPaX} 2$; third generation lentivirus packaging system (vector: Packaging vector: Envelope ratio, 10:3:1) Promega Corporation] were co-transfected into $1 \times 10^{6} 293$ T cells (Cell Bank of the Chinese Academy of Sciences) with Lipofectamine ${ }^{\circledR} 3000$ (Invitrogen; Thermo Fisher Scientific, Inc.). Following cell culture of the 293 T cells for 4 days, cell supernatant was collected and centrifuged at $251.55 \mathrm{x} \mathrm{g}$ for $5 \mathrm{~min}$ at $37^{\circ} \mathrm{C}$. The supernatant was subsequently filtered using a $0.22 \mu \mathrm{M}$ membrane to collect the Fas overexpression lentivirus (OE-Fas), empty lentivirus (OE-NC), Fas knockdown lentivirus (sh-Fas) and knockdown $\mathrm{NC}$ lentivirus (KD-NC) vectors. JAR cells $\left(\sim 1 \times 10^{6}\right)$ were then infected with the lentiviral vectors at $37^{\circ} \mathrm{C}$, at a multiplicity of infection value $=25$. The transfected cells were collected $96 \mathrm{~h}$ after infection to determine the infection efficiency. The following experiment was conducted $96 \mathrm{~h}$ after transfection.

NF- $\kappa B$ p 65 overexpression. An NF- $\mathrm{B}$ p 65 sequence (GenBank ID: NM_021975) was cloned into an LV003 vector (Invitrogen; Thermo Fisher Scientific, Inc.) to prepare a NF-кB p65 overexpression vector. Empty LV003 vector was used as a control. The JAR cells were cultured to $\sim 80 \%$ confluence, and then transfected with the Fas knockdown lentiviral vector (sh-Fas) and/or the LV003 vector harboring the NF- $\mathrm{B}$ p65 sequence or empty LV003 control using Lipofectamine 3000 reagent. After continuous culture for $12 \mathrm{~h}$, the conventional medium without virus was replaced and cells were cultured at $37^{\circ} \mathrm{C}$. Subsequent experiments were conducted following $48 \mathrm{~h}$ of transfection.

Reverse transcription-quantitative PCR (RT-qPCR). RNAiso Plus (Takara Bio, Inc.) was used to isolate total RNA from the transfected trophoblast cells. Complementary DNA (cDNA) was produced from the RNA using a PrimeScript ${ }^{\mathrm{TM}}$ RT Reagent kit with gDNA Eraser, according to the manufacturer's instructions (Takara Bio, Inc.). The cDNA was subjected to qPCR using SYBRGreen Realtime PCR kit (Takara Bio, Inc.). qPCR was performed using 30 cycles at $42^{\circ} \mathrm{C}$ for $30 \mathrm{~min}$ and $95^{\circ} \mathrm{C}$ for $5 \mathrm{~min}$. The following components were used in a total reaction volume of $25 \mu \mathrm{l}$ : cDNA $(2 \mu \mathrm{l})$, SYBR Premix $\operatorname{Ex~Taq}^{\mathrm{TM}}(2 \mathrm{X} ; 10 \mu \mathrm{l})$, reverse primer $(10 \mu \mathrm{M} ; 1 \mu \mathrm{l})$, forward primer $(10 \mu \mathrm{M} ; 1 \mu \mathrm{l})$, double-distilled water $(10 \mu \mathrm{l})$ and ROX Reference dye II (1:50 in PBS; $1 \mu \mathrm{l})$. Relative expression of the target mRNA was normalized to the expression of GAPDH mRNA and calculated using the $2^{-\Delta \Delta \mathrm{Cq}}$ method (21). The sequences of the primers used were as follows: GAPDH (gene accession no. CH471116) forward, 5'-TGACTTCAACAG CGACACCCA-3' and reverse, 5'-CACCCTGTTGCTGTA GCCAAA-3'; Fas (gene accession no. AH006106) forward, 5'-CTTCTTTTGCCAATTCCAC-3' and reverse, 5'-CAGATA AATTTATTGCCACTG-3'; and RELA (also known as p65; gene accession no. AY455868) forward, 5'-GACTACGACCTG AATGCTGTG-3' and reverse, 5'-ACCTCAATGTCCTCT TTCTGC-3'.

Cell viability assay. Transfected trophoblast cells were seeded in 96-well cell culture plates at a density of $2 \times 10^{3}$ cells/well and cultured in an incubator for $48 \mathrm{~h}$. Next, Cell Counting Kit-8 (CCK-8) reagent (10 $\mu$ l/well; MedChemExpress) was added to the cells and incubated for $2 \mathrm{~h}$ at $37^{\circ} \mathrm{C}$. A spectrometer (Thermo Fisher Scientific, Inc.) was used to measure the absorbance at $450 \mathrm{~nm}$. The cell viability was calculated from the absorbance values each day for 5 consecutive days.

Apoptosis analysis. An Annexin V-FITC/7AAD kit (BioLegend, Inc.) was used to detect cell apoptosis following the manufacturer's instructions. The trophoblast cells in the logarithmic growth phase after transfection were harvested and digested with $0.25 \%$ trypsin for $2 \mathrm{~min}$ at $37^{\circ} \mathrm{C}$ The cells were centrifuged at $400 \mathrm{x} \mathrm{g}$ for $3 \mathrm{~min}$ at $37^{\circ} \mathrm{C}$, and subsequently washed twice with cold PBS. The cells were re-suspended in $500 \mu \mathrm{l}$ binding buffer to a final concentration of $1 \times 10^{6}$ cells $/ \mathrm{ml}$. A $100-\mu 1$ portion of the cell suspension was transferred to a 5-ml flow tube into which $5 \mu \mathrm{l}$ 7-AAD and $5 \mu \mathrm{l}$ Annexin V-PE were added. The contents in the flow tube were mixed and incubated for $15 \mathrm{~min}$ in the dark. A flow cytometer (CytoFLEX; Beckman Coulter, Inc.) was used to examine the cells and FlowJo software (Version 10; Tree Star, Inc.) was used to analyze the data.

Cell migration assay. A Transwell assay was conducted to measure the changes in trophoblast cell migration after transfection. The transfected cells were washed three 
times using serum-free DMEM (cat no. A4192101; Gibco; Thermo Fisher Scientific, Inc.) medium and counted. The cells were suspended in the medium at a concentration of 7,000 cells/well in a 12 -well plate $(3,500$ cells $/ \mathrm{ml})$. Then, $150 \mu 1$ serum-free cell suspension and $600 \mu 1$ DMEM supplemented with 10\% FBS (cat. no. 16140071; Gibco; Thermo Fisher Scientific, Inc.) were added to the lower and upper chambers of the Transwell apparatus, respectively, and the Transwell was incubated for $48 \mathrm{~h}$ at $37^{\circ} \mathrm{C}$ in an incubator. The cells on the basolateral chamber were washed twice using PBS, and stained with $1 \%$ crystal violet for $30 \mathrm{~min}$ at $37^{\circ} \mathrm{C}$. The cells were then washed twice using PBS and images captured under a microscope (magnification, x200; Olympus cX2; Olympus Corporation).

Tumor necrosis factor $\alpha(T N F-a)$ and interleukin-2 (IL-2) measurement. The levels of TNF- $\alpha$ and IL-2 in the supernatant of the trophoblast cells were detected using enzyme-linked immunosorbent assay kits (cat. nos. RAB0480 and RAB0286, respectively; Merck KGaA). The calibration curves were plotted on semi-log papers, and the concentrations of TNF- $\alpha$ and IL-2 were determined based on a comparison of the optical density values of the samples with the standard curve.

Western blot analysis. Transfected cells were washed three times with cold PBS and proteins were extracted from the cells using RIPA lysis buffer (cat. no. HY-K1001; MedChemExpress). The protein concentration was quantified using a BCA Protein assay kit (cat. no. 23225; Thermo Fisher Scientific, Inc.). The protein samples (30 $\mu \mathrm{g} / \mathrm{lane})$ were resolved using 20\% Precise Protein Gels (Pierce; Thermo Fisher Scientific, Inc.) and transferred to polypropylene fluoride membranes (Amersham; Cytiva). The membranes were blocked for $1 \mathrm{~h}$ at room temperature with 3\% skimmed milk in Tris-buffered saline (TBS) containing $0.1 \%$ Tween 20 . The membranes were then probed using primary antibodies against Fas (cat. no. 8023), Bax (cat. no. 14796), NF-кB p65 (cat. no. 8242), Bcl-2 (cat. no. 15071) and b-actin (cat. no. 3700). All antibodies were bought from Cell Signaling Technology, Inc. The blots were then washed in TBS containing $0.1 \%$ Tween-20 prior to labelling with horseradish peroxidase-conjugated secondary anti-rabbit antibody for $2 \mathrm{~h}$ at room temperature (cat. no. $4414 \mathrm{~S}$; Cell Signaling Technology, Inc.). The primary antibodies were used at a dilution of 1:1,000 and the secondary antibody was used at a dilution of 1:5,000 according to the manufacturer's instructions. The blots were visualized using an ECL plus Western Blotting Detection System (Amersham; Cytiva). Relative protein expression levels were normalized to the expression of b-actin. Image J (version 1.48, National Institutes of Health) was used for densitometric analysis.

Statistical analysis. Statistical analysis was performed using GraphPad Prism software (8.0; GraphPad Software, Inc.). Each experiment was repeated three times, Data are presented as the mean \pm standard deviation. Differences between groups were compared using one-way ANOVA analysis followed by Tukey's post hoc test. $\mathrm{P}<0.05$ was considered to indicate a statistically significant difference.

\section{Results}

Transfection effectively modulates Fas $m R N A$ and protein expression. Fluorescence imaging indicated that the transfection efficiency in each group of trophoblast cells was $>80 \%$ (Fig. 1A). The RT-qPCR analysis revealed that the Fas mRNA level of the trophoblast cells in the OE-Fas group was $251 \%$ that of the OE-NC group, whereas the Fas mRNA level in the sh-Fas group was $26.04 \%$ that of the KD-NC group (Fig. 1B). Western blotting results indicated that the protein expression of Fas in trophoblast cells in the OE-Fas group was significantly higher compared with that in the OE-NC group, while the protein expression of Fas in the sh-Fas group was significantly lower compared with that in the KD-NC group (Fig. 1C and D).

Fas regulates the apoptosis and migration of trophoblast cells. Flow cytometry results indicated that the apoptosis of the trophoblast cells was significantly promoted by the overexpression of Fas and suppressed by the knockdown of Fas (Fig. 2A and B). In addition, the results of the Transwell assay indicated that the overexpression of Fas inhibited trophoblast cell migration, while the knockdown of Fas significantly promoted trophoblast cell migration (Fig. 2C and D). Moreover, the CCK- 8 assay results revealed that the viability of the trophoblast cells was reduced by the overexpression of Fas and increased by the knockdown of Fas (Fig. 2E). Furthermore, the overexpression of Fas in trophoblast cells upregulated the secretion of TNF- $\alpha$ and IL-2 while the knockdown of Fas decreased this secretion (Fig. 2F and G).

Fas may function via $N F-\kappa B$. Western blot analysis indicated that the overexpression of Fas in trophoblast cells significantly upregulated the expression of NF- $\mathrm{\kappa B}$ and $\mathrm{Bax}$ and significantly decreased the expression of Bcl-2 (Fig. 3A-D). By contrast, the knockdown of Fas in trophoblast cells significantly decreased the expression of NF- $\mathrm{KB}$ and Bax and significantly upregulated the expression of Bcl-2 (Fig. 3A-D). To further investigate the involvement of NF- $\mathrm{kB}$ in the Fas-mediated apoptosis and migration of trophoblast cells, NF- $\mathrm{kB}$ p65 was overexpressed in the JAR cells (Fig. 3E). Notably, the overexpression of NF- $\kappa B$ reversed the Fas knockdown-induced inhibitory effects on apoptosis and stimulatory effects on migration in trophoblast cells (Fig. 3F and G). In addition, the overexpression of NF- $\mathrm{KB}$ in trophoblast cells attenuated the reduction in Bax expression and increase in $\mathrm{Bcl}-2$ expression induced by Fas knockdown (Fig. 3H-K). These results indicate that Fas regulates the apoptosis and migration of trophoblast cells via NF- $\mathrm{kB}$.

\section{Discussion}

Women with preeclampsia are more likely than those without preeclampsia to have pre-term births (22). Preeclampsia may lead to eclampsia-associated complications, including shaking, coma, heart problems, placental abruption and renal impedance (23). Studies have reported that trophoblast migration is associated with the onset of preeclampsia $(4,24)$.

Trophoblast apoptosis has been confirmed to occur in the placental tissue during pregnancy (25). The excessive apoptosis of placental trophoblasts leads to shallow implantation and the 

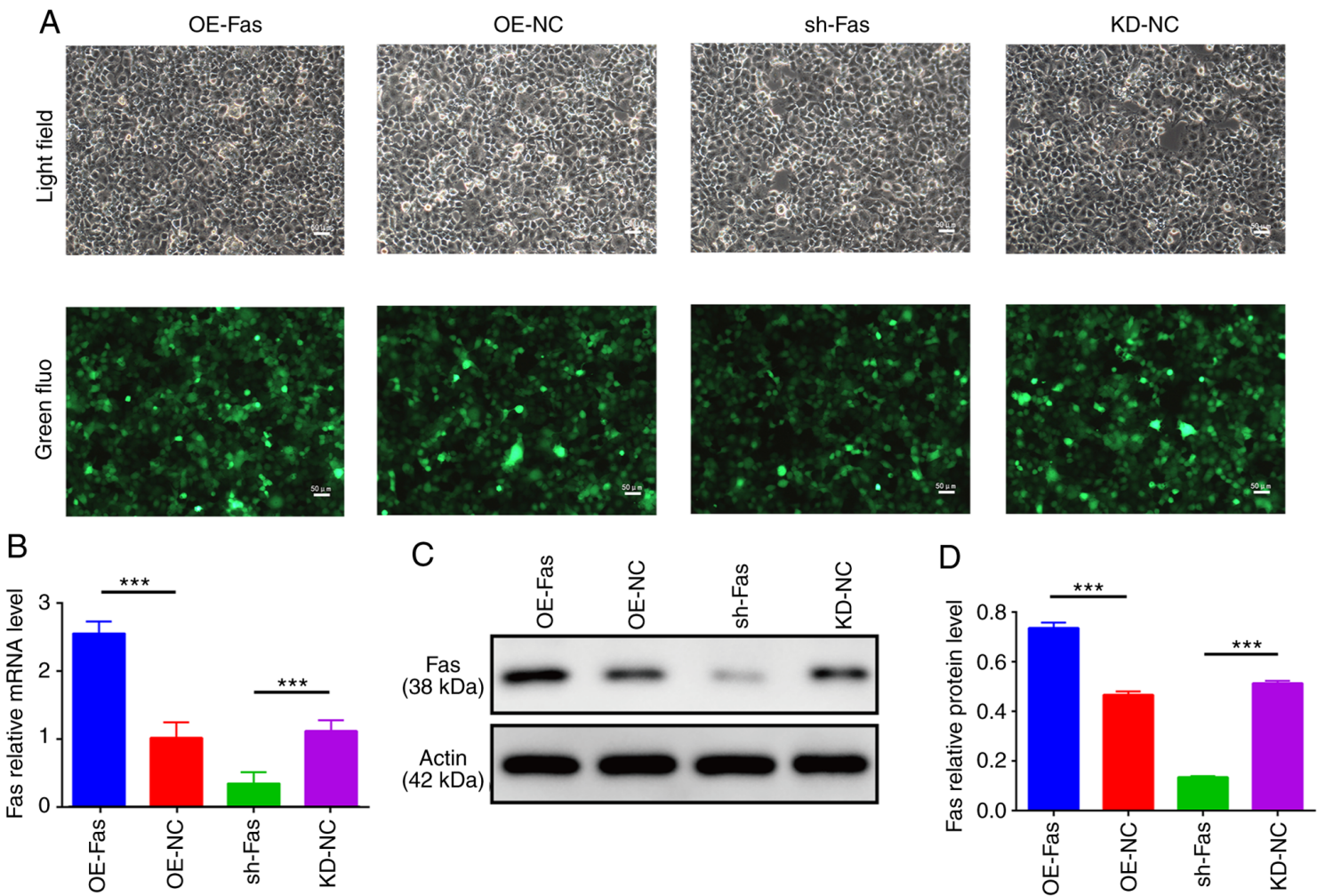

Figure 1. Fas overexpression and knockdown vectors were successfully constructed. (A) The transfection efficiency of Fas in trophoblast cells analyzed using fluorescence imaging. (B) The mRNA level of Fas in transfected trophoblast cells. (C) Western blotting of Fas in transfected trophoblast cells. (D) The protein level of Fas was quantified by densitometry and normalized to the expression of $\beta$-actin. Results are expressed as the mean $\pm \mathrm{SD}(\mathrm{n}=3)$. ${ }^{* * * *} \mathrm{P}<0.001$. OE, overexpression; NC, negative control; KD, knockdown; sh, short hairpin.
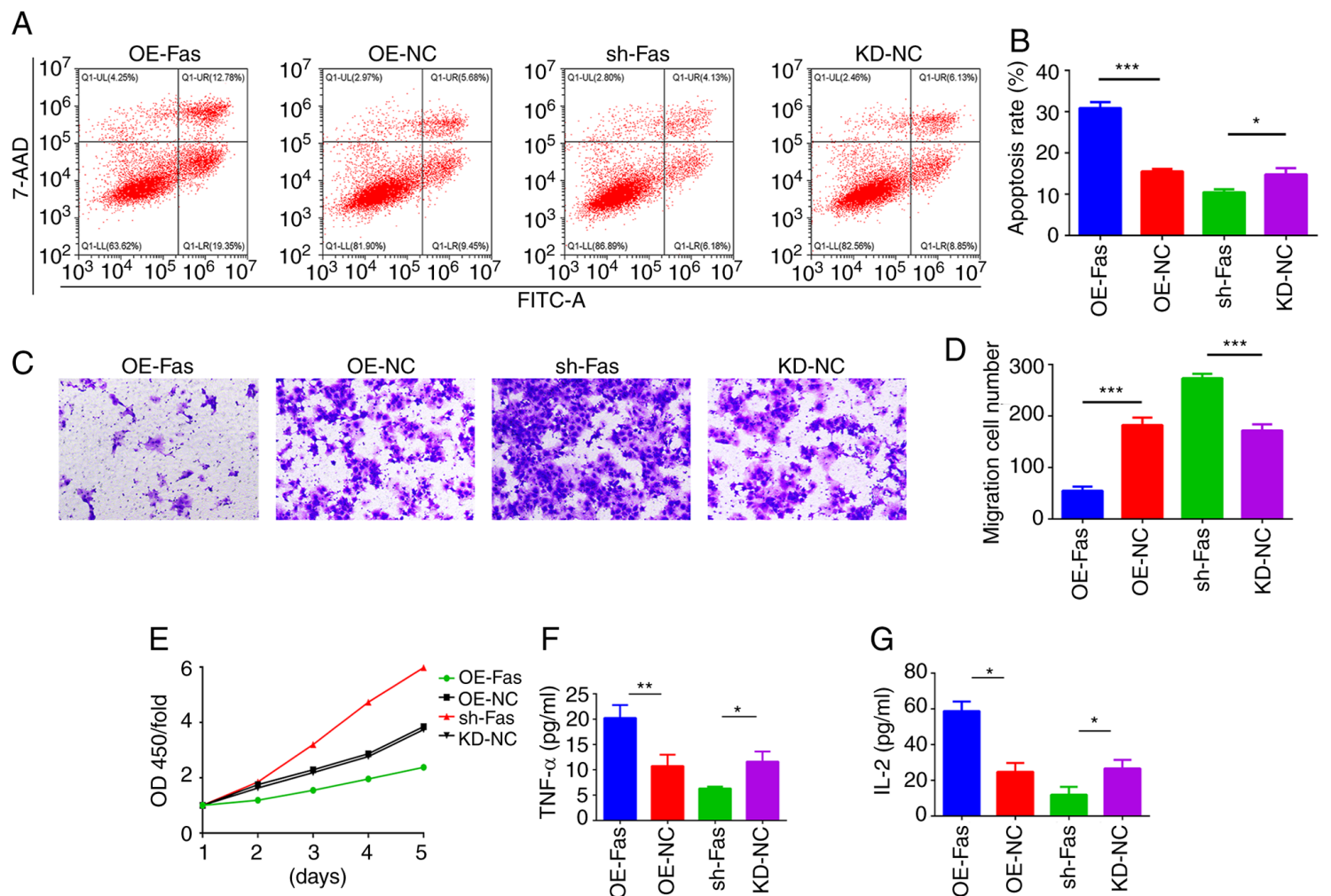

$\mathrm{F}$

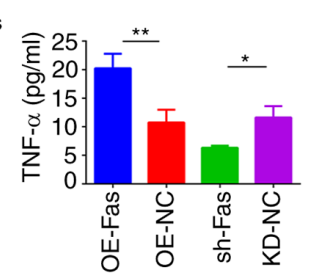

G

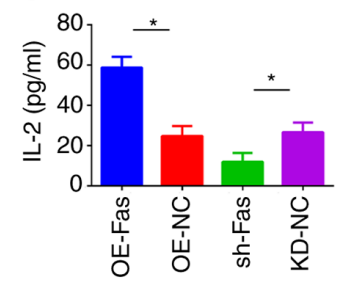

Figure 2. Fas regulates the apoptosis and migration of trophoblast cells. (A) The apoptosis of transfected trophoblast cell cells was evaluated using flow cytometry via the measurement of FITC-Annexin V and 7AAD labeling. (B) The percentage of apoptotic cells in each group. (C) Representative images of the in vitro migration ability of trophoblast cells evaluated using a Transwell assay (magnification, $\mathrm{x} 200$ ). (D) Quantification of the migration rate in three separate experiments. (E) measured Trophoblast cell viability evaluated using a Cell Counting Kit- 8 assay. The levels of (F) TNF- $\alpha$ and (G) IL-2 in the supernatant of the trophoblast cells detected using ELISAs. Results are expressed as mean $\pm \mathrm{SD}(\mathrm{n}=3)$. ${ }^{*} \mathrm{P}<0.05,{ }^{* * *} \mathrm{P}<0.01$ and ${ }^{* * *} \mathrm{P}<0.001$. OE, overexpression; NC, negative control; KD, knockdown; sh, short hairpin; OD450, optical density at $450 \mathrm{~nm}$; TNF- $\alpha$, tumor necrosis factor $\alpha$; IL-2, interleukin-2. 

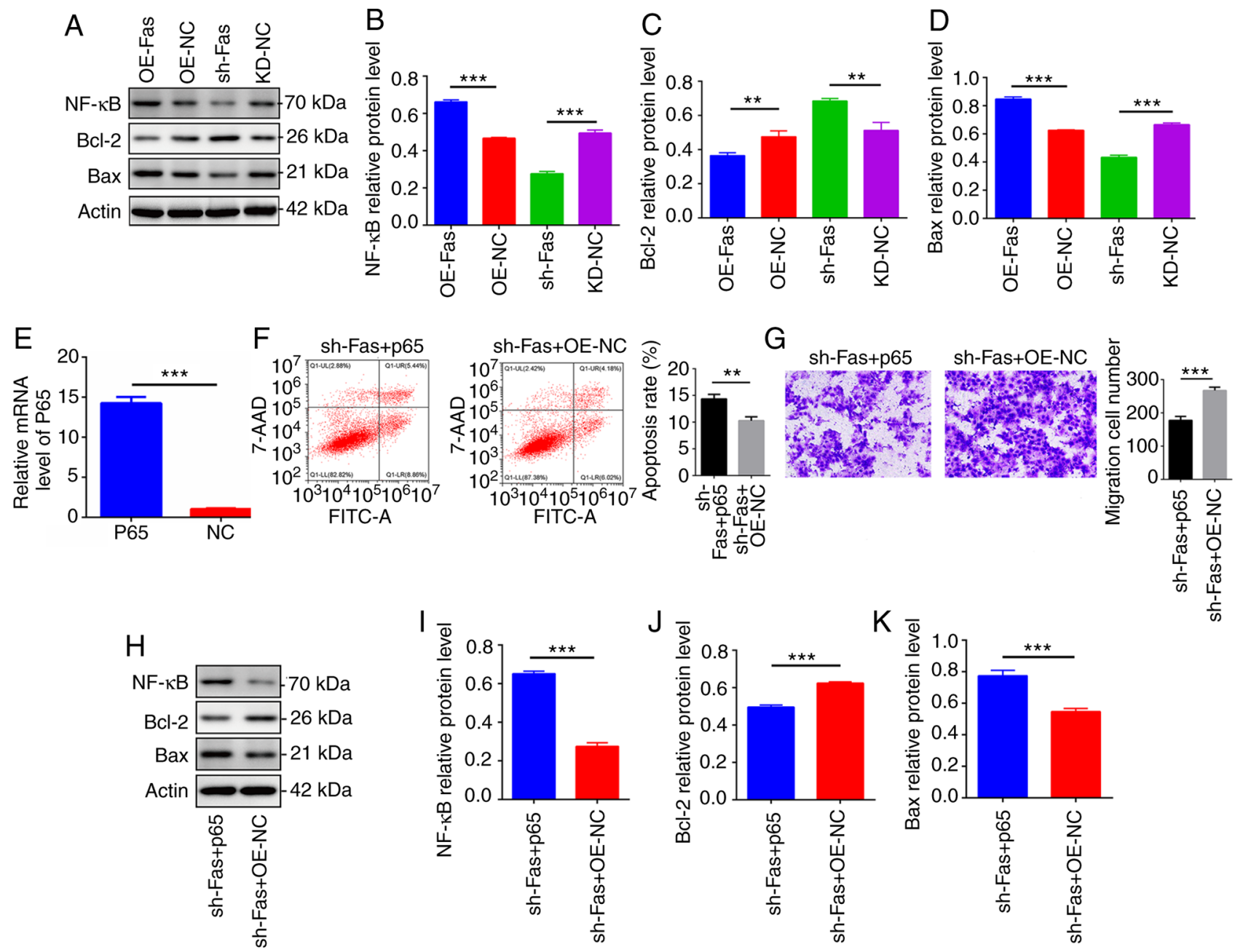

Figure 3. Overexpression of NF-kB reversed the Fas knockdown-mediated promotion of apoptosis and inhibition of cell migration. (A) Protein levels of NF- $\mathrm{KB}, \mathrm{Bcl}-2$ and Bax in trophoblast cells transfected with OE-Fas, OE-NC, shRNA-Fas and KD-NC examined using western blot analysis. The protein levels of (B) NF-kB, (C) Bcl-2 and (D) Bax were quantified by densitometry and normalized to the expression of $\beta$-actin. (E) Measurement of the mRNA level of

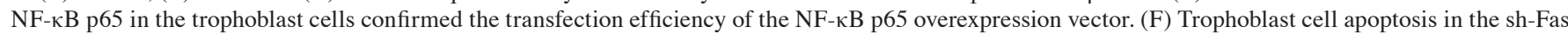
+ p65 and sh-Fas + OE-NC groups was evaluated using flow cytometry and the percentage of apoptotic cells in each group is shown. (G) The migration ability of trophoblast cells in the sh-Fas + p65 and sh-Fas + OE-NC groups was examined using a Transwell assay (magnification, x200). Quantification of the migration rate in three separate experiments is shown. $(\mathrm{H})$ Representative western blots showing the protein levels of NF- $\mathrm{BB}, \mathrm{Bcl}-2$ and Bax in the sh-Fas + p65 and sh-Fas + OE-NC groups of trophoblast cells. Protein levels of (I) NF- $\mathrm{KB}$, (J) Bcl-2 and (K) Bax were quantified by densitometry and normalized to the expression of $\beta$-actin. Results are expressed as the mean $\pm \mathrm{SD}(\mathrm{n}=3){ }^{* * *} \mathrm{P}<0.01$ and ${ }^{* * * *} \mathrm{P}<0.001$. OE, overexpression; NC, negative control; KD, knockdown; sh, short hairpin; NF- $\mathrm{kB}$, nuclear factor $\kappa \mathrm{B}$.

failure of uterine spiral artery reconstruction. Eventually, this decreases placental blood perfusion, leading to preeclampsia. Therefore, the apoptosis and migration of placental trophoblasts are important processes contributing to the development of preeclampsia $(23,26)$.

FasL is a natural ligand of Fas that is encoded by a gene with five exons located on chromosome 1q23 region. It belongs to the TNF family and is a type I membrane protein. The FasL cDNA contains 1,623 nucleotides that encode a peptide composed of 278 amino acids linking with a signal sequence at the N-terminus (24). Several studies have reported that Fas and FasL gene polymorphisms play important roles in the development of preeclampsia (27-29). However, the involvement of Fas in the apoptosis, viability and migration of placental trophoblasts remains unclear. The present study demonstrated that the overexpression of Fas in trophoblast cells induced apoptosis and decreased the viability and migration of the cells. Moreover, it increased the expression of TNF- $\alpha$, IL-2 and Bax, and decreased the expression of Bcl-2. These results indicate that increased Fas expression stimulated an inflammatory response and cell apoptosis. By contrast, the knockdown of Fas suppressed the apoptosis of trophoblast cells, and significantly increased trophoblast viability and migration. These results are consistent with the role served by Fas in osteosarcoma (30), cervical cancer (31), lung cancer (32) and breast cancer (33). The knockdown of Fas decreased the expression of TNF- $\alpha$, IL-2 and Bax, and increased the expression of Bcl-2. These results indicate that the knockdown of Fas suppressed the inflammatory response and apoptosis of the trophoblast cells.

NF- $\mathrm{KB}$ has been studied as an inflammatory activator in preeclampsia (34-36). However, the specific mechanism underlying the effects of NF- $\mathrm{KB}$ in preeclampsia has not been elucidated. The present study has demonstrated that Fas is 
able to regulate the expression of NF- $\mathrm{KB}$. Notably, the overexpression of NF- $\mathrm{kB}$ reversed the Fas knockdown-mediated suppression of cell apoptosis and increase in the migration of trophoblast cells. These results suggest that NF- $\mathrm{KB}$ may be regulated by Fas in preeclampsia.

The present study has certain limitations. The potential interaction between Fas and NF- $\mathrm{KB}$ was not verified. In addition, only in vitro experiments were performed, and it is necessary to establish an animal model to validate the role of Fas in preeclampsia. Another limitation of the present study is that only one cell line, JAR, was used. Therefore, the findings of the present study require validation in other cell lines and animal models in the future.

In conclusion, the present study suggests that the Fas gene regulates the apoptosis and migration of trophoblast cells by targeting NF-kB. These findings indicate the importance of Fas in the induction of apoptosis and inhibition of migration of normal trophoblast cells. As the present study demonstrates that Fas inhibits the viability and migration of trophoblast cells by targeting NF- $\mathrm{kB}$, the silencing of Fas may be a promising therapeutic strategy for the treatment of preeclampsia.

\section{Acknowledgements}

Not applicable.

\section{Funding}

This study was supported by the Natural Science Foundation of Hainan Province (grant no. 818MS123).

\section{Availability of data and materials}

All data generated or analyzed during this study are included in this published article.

\section{Authors' contributions}

RL carried out cell detection and writing, YY carried out cell detection and writing, JS completed the construction of the vector, LW analyzed the data and HG provided funding and experimental design. RL and YY confirm the authenticity of all the raw data. All authors read and approved the final manuscript.

\section{Ethics approval and consent to participate}

Not applicable.

\section{Patient consent for publication}

Not applicable.

\section{Competing interests}

The authors declare that they have no competing interests.

\section{Authors' information}

ORCID for Humin Gong: https://orcid.org/0000-0003-17395988 .

\section{References}

1. Broumand F, Lak SS, Nemati F and Mazidi A: A study of the diagnostic value of inhibin a tests for occurrence of preeclampsia in pregnant women. Electronic Physician 10: 6186-6192, 2018.

2. Gestational hypertension and preeclampsia: ACOG practice bulletin, number 222. Obstet Gynecol 135: e237-e260, 2020.

3. Phipps EA, Thadhani R, Benzing T and Karumanchi SA: Author correction: Pre-eclampsia: Pathogenesis, novel diagnostics and therapies. Nat Rev Nephrol 15: 386, 2019.

4. James-Allan LB, Whitley GS, Leslie K, Wallace AE and Cartwright JE: Decidual regulation of trophoblast is altered in pregnancies at risk of pre-eclampsia. J Mol Endocrinol 60: 239-246, 2018.

5. Ngene NC and Moodley J: Role of angiogenic factors in the pathogenesis and management of pre-eclampsia. Int J Gynaecol Obstet 141: 5-13, 2018.

6. Possomato-Vieira JS and Khalil RA: Mechanisms of endothelial dysfunction in hypertensive pregnancy and preeclampsia. Adv Pharmacol 77: 361-431, 2016.

7. Kaufmann P, Black S and Huppertz B: Endovascular trophoblast invasion: Implications for the pathogenesis of intrauterine growth retardation and preeclampsia. Biol Reprod 1: 1-7, 2003.

8. Mol BWJ, Roberts CT, Thangaratinam S, Magee LA, de Groot CJM and Hofmeyr GJ: Pre-eclampsia. Lancet 387: 999-1011, 2016.

9. Zha W, Guan S, Liu N, Li Y, Tian Y, Chen Y, Wang Y and Wu F: Let-7a inhibits Bcl-xl and YAP1 expression to induce apoptosis of trophoblast cells in early-onset severe preeclampsia. Sci Total Environ 745: 139919, 2020.

10. Wang D, Na Q, Song GY and Wang L: Human umbilical cord mesenchymal stem cell-derived exosome-mediated transfer of microRNA-133b boosts trophoblast cell proliferation, migration and invasion in preeclampsia by restricting SGK1. Cell Cycle 19: 1869-1883, 2020

11. Mo HQ, Tian FJ, Ma XL, Zhang YC, Zhang CX, Zeng WH, Zhang Y and Lin Y: PDIA3 regulates trophoblast apoptosis and proliferation in preeclampsia via the MDM2/p53 pathway. Reproduction 160: 293-305, 2020.

12. Cai G, Si M, Li X, Zou H, Gu J, Yuan Y, Liu X, Liu Z and Bian J: Zearalenone induces apoptosis of rat Sertoli cells through Fas-Fas ligand and mitochondrial pathway. Environ Toxicol 34: 424-433, 2019.

13. Mor G, Straszewski S and Kamsteeg M: Role of the Fas/Fas ligand system in female reproductive organs: Survival and apoptosis. Biochem Pharmacol 64: 1305-1315, 2002.

14. Wang T and Lian Y: The relationship between Fas and Fas ligand gene polymorphism and preeclampsia risk. Biosci Rep 39: BSR20181901, 2019.

15. Shi L, Gong HM and Ru MY: The relationship between Fas \& Bcl-2 and cell apoptosis in placenta and their significance in pathogenesis of preeclampsia. Mod Prev Med 40: 2421-2425, 2013 (In Chinese).

16. Shi L, Gong HM and Ru MY: Expressions and significances of Fas/FasL and Bcl-2 in placentae of cases with preeclampsia. Maternal and Child Health Care of China 26: 3291-3294, 2011 (In Chinese).

17. Mitchell S, Vargas J and Hoffmann A: Signaling via the $\mathrm{NF \kappa}_{\mathrm{B}}$ system. Wiley Interdiscip Rev Syst Biol Med 8: 227-241, 2016.

18. Zheng L, Shi L, Zhou Z, Chen X, Wang L, Lu Z and Tang R: Placental expression of AChE, $\alpha 7 \mathrm{nAChR}$ and NF- $\kappa \mathrm{B}$ in patients with preeclampsia. Ginekol Pol 89: 249-255, 2018.

19. Vaughan JE and Walsh SW: Activation of NF- $\kappa B$ in placentas of women with preeclampsia. Hypertens Pregnancy 31: 243-251, 2012.

20. Vora S, Abbas A, Kim CJ, Summerfield TL, Kusanovic JP, Iams JD, Romero R, Kniss DA and Ackerman WE IV: Nuclear factor-kappa B localization and function within intrauterine tissues from term and preterm labor and cultured fetal membranes. Reprod Biol Endocrinol 8: 8, 2010.

21. Livak KJ and Schmittgen TD: Analysis of relative gene expression data using real-time quantitative PCR and the 2(-Delta Delta C(T)) method. Methods 25: 402-408, 2001.

22. Davies EL, Bell JS and Bhattacharya S: Preeclampsia and preterm delivery: A population-based case-control study. Hypertens Pregnancy 35: 510-519, 2016.

23. Sones JL and Davisson RL: Preeclampsia, of mice and women. Physiol Genomics 48: 565-572, 2016.

24. Namdev S, Bhat V, Adhisivam B and Zachariah B: Oxidative stress and antioxidant status among neonates born to mothers with pre-eclampsia and their early outcome. J Matern Fetal Neonatal Med 27: 1481-1484, 2014. 
25. Khovhaeva PA, Krasniy AM, Tyutyunnik NV, Sergunina OA, Ganichkina MB, Amiraslanov EY, Kan NE and Tyutyunnik VL: Placental apoptosis in pre-eclampsia. Med Counc: 102-104, 2016 (In Russian)

26. Ma XP, Liu CD, Cao GM and Zhang ZY: Transthyretin increases migration and invasion of rat placental trophoblast cells. FEBS Open Bio 10: 1568-1576, 2020.

27. Tang R, Mei X, Wang YC, Cui XB, Zhang G, Li W and Chen SY: LncRNA GAS5 regulates vascular smooth muscle cell cycle arrest and apoptosis via 533 pathway. Biochim Biophys Acta Mol Basis Dis 1865: 2516-2525, 2019.

28. Han AR, Choi YM, Hong MA, Kim JJ, Lee SK, Yang KM Paik EC, Jeong HJ and Jun JK: Fas and FasL genetic polymorphisms in women with recurrent pregnancy loss: A case-control study. Hum Fertil (Camb) 22: 198-203, 2019.

29. Darmochwal-Kolarz D, Leszczynska-Gorzelak B, Rolinski J and Oleszczuk J: The expression and concentrations of Fas/APO-1 (CD95) antigen in patients with severe pre-eclampsia. J Reprod Immunol 49: 153-164, 2001.

30. Hollomon MG, Patterson L, Santiago-O'Farrill J, Kleinerman ES and Gordon N: Knock down of Fas-associated protein with death domain (FADD) sensitizes osteosarcoma to TNF $\alpha$-induced cell death. J Cancer 11: 1657-1667, 2020.

31. Tan SC, Ismail MP, Duski DR, Othman NH and Ankathil R: FAS c.-671 A $>$ G polymorphism and cervical cancer risk: A case-control study and meta-analysis. Cancer Genet 211: 18-25, 2017.
32. Kiany S, Harrison D and Gordon N: The histone deacetylase inhibitor entinostat/syndax 275 in osteosarcoma. Adv Exp Med Biol 1257: 75-83, 2020.

33. Kolben T, Jeschke U, Reimer T, Karsten N, Schmoeckel E, Semmlinger A, Mahner S, Harbeck N and Kolben TM: Induction of apoptosis in breast cancer cells in vitro by Fas ligand reverse signaling. J Cancer Res Clin Oncol 144: 249-256, 2018.

34. Xue P, Fan W, Diao Z, Li Y, Kong C, Dai X, Peng Y, Chen L, Wang $\mathrm{H}, \mathrm{Hu} \mathrm{Y}$ and $\mathrm{Hu} \mathrm{Z}$ : Up-regulation of PTEN via LPS/AP-1/NF- $\kappa$ B pathway inhibits trophoblast invasion contributing to preeclampsia. Mol Immunol 118: 182-190, 2020.

35. Eddy AC, Howell JA, Chapman H, Taylor E, Mahdi F, George EM and Bidwell GL III: Biopolymer-delivered, maternally sequestered NF- $\kappa \mathrm{B}$ (nuclear factor- $\kappa \mathrm{B}$ ) inhibitory peptide for treatment of preeclampsia. Hypertension 75: 193-201, 2020.

36. Kim S, Lee KS, Choi S, Kim J, Lee DK, Park M, Park W, Kim TH, Hwang JY, Won MH, et al: NF- $\mathrm{KB}$-responsive miRNA-31-5p elicits endothelial dysfunction associated with preeclampsia via down-regulation of endothelial nitric-oxide synthase. J Biol Chem 293: 18989-19000, 2018

This work is licensed under a Creative Commons Attribution-NonCommercial-NoDerivatives 4.0 International (CC BY-NC-ND 4.0) License. 